\title{
Lack of flagella disadvantages Salmonella enterica serovar Enteritidis during the early stages of infection in the rat
}

\author{
Correspondence \\ George Grant \\ G.Grant@rowett.ac.uk
}

Received 15 February 2002

Accepted 11 September 2002

\author{
Jeanette M. C. Robertson, ${ }^{1}+$ Norma H. McKenzie, ${ }^{1}$ Michelle Duncan, ${ }^{1}$ \\ Emma Allen-Vercoe, ${ }^{2} \neq$ Martin J. Woodward, ${ }^{2}$ Harry J. Flint ${ }^{1}$ \\ and George Grant ${ }^{1}$
}

${ }^{1}$ Gut Microbiology and Immunology Division, Rowett Research Institute, Greenburn Road, Bucksburn, Aberdeen AB21 9SB, UK

${ }^{2}$ Department of Bacterial Diseases, Veterinary Laboratories Agency (Weybridge), Addlestone, Surrey KT15 3NB, UK

\begin{abstract}
The roles of flagella and five fimbriae (SEF14, SEF17, SEF21, pef, Ipf) in the early stages (up to 3 days) of Salmonella enterica serovar Enteritidis ( $S$. Enteritidis) infection have been investigated in the rat. Wild-type strains LA5 and $\mathrm{S} 1400(\mathrm{fim}+/ \mathrm{fla}+)$ and insertionally inactivated mutants unable to express the five fimbriae (fim-/fla+), flagella (fim+/fla-) or fimbriae and flagella (fim-/fla-) were used. All wild-type and mutant strains were able to colonize the gut and spread to the mesenteric lymph nodes, liver and spleen. There appeared to be little or no difference between the fim -/fla+ and wild-type (fim+/fla+) strains. In contrast, the numbers of aflagellate (fim+/fla- or fim-/fla-) salmonella in the liver and spleen were transiently reduced. In addition, fim+/fla - or fim -/flastrains were less able to persist in the upper gastrointestinal tract and the inflammatory responses they elicited in the gut were less severe. Thus, expression of SEF14, SEF17, SEF21, pef and lpf did not appear to be a prerequisite for induction of $S$. Enteritidis infection in the rat. Deletion of flagella did, however, disadvantage the bacterium. This may be due to the inability to produce or release the potent immunomodulating protein flagellin.
\end{abstract}

\section{INTRODUCTION}

Infections caused by Salmonella enterica serovars Enteritidis (S. Enteritidis) and Typhimurium (S. Typhimurium) continue to be a major health problem. They usually occur after consumption of contaminated food or water and can manifest in a variety of disease states, ranging from asymptomatic carrier status through to gastroenteritis or even severe systemic infection that can lead to death (Tsolis et al., 1999; Kingsley \& Baumler, 2000; Ohl \& Miller, 2001). The nature and severity of the infection varies according to bacterial strain. It can also be greatly influenced by host factors, such as species, age and health status. Immunocompromised individuals are particularly susceptible to the pathogen. The majority of cases, both in humans and domesticated animals, are of a self-limiting gastroenteritis type.

†Present address: Centre for Environmental Engineering and Sustainable Energy, The Robert Gordon University, Schoolhill, Aberdeen AB10 1FR, UK.

‡Present address: Health Sciences Centre, 3330 Hospital Drive NW, Calgary, Alberta, Canada T2N 4N1.

Abbreviation: MPO, myeloperoxidase.
The pathogenicity of salmonella is linked to a number of virulence factors, including adhesins, flagella, enzymes, toxins and other bioactive factors. These facilitate adherence to the gut, invasion, systemic spread and survival and proliferation in systemic organs (Tsolis et al., 1999; Kingsley \& Baumler, 2000; Ohl \& Miller, 2001; Darwin \& Miller, 1999; Humphries et al., 2001; Galan, 2001). Attachment of the pathogen to the gut is a key initial step in the infection process. Mediation of attachment primarily by bacterial (fimbrial) adhesins has been suggested (Kingsley \& Baumler, 2000; Darwin \& Miller, 1999; Humphries et al., 2001). However, recent studies suggest that other factors might also be involved (Allen-Vercoe et al., 1999; Allen-Vercoe \& Woodward, 1999; Robertson et al., 2000; Robertson, 2000). $S$. Enteritidis mutant strains unable to express functional flagella were less able to attach to explants in vitro and less pathogenic to chicks in vivo (Allen-Vercoe et al., 1999; AllenVercoe \& Woodward, 1999; Robertson et al., 2000; Robertson, 2000).

The aim of the present study was to evaluate the roles of fimbriae and flagella in the early stages of $S$. Enteritidis infection in a mammalian host. A rat model of salmonellosis 
was used (Naughton et al., 1995, 1996a). Salmonella sp. colonize the whole gastrointestinal tract of the rat and cause disruption of the small intestine epithelium, epithelial cell hyperplasia and infiltration by inflammatory cells (Naughton et al., 1995, 1996a, 2000; Havelaar et al., 2001; Islam et al., 2000). Invasion is mainly via the ileum; large numbers of salmonella reach the mesenteric lymph nodes and moderate numbers spread to and persist in the liver and spleen. Rats continue to grow, albeit slowly, and death due to infection is rare, unless health or immune status or gut integrity has been compromised by other factors. Salmonellosis in the rat thus has many similarities to the self-limiting gastroenteritis-type infection common in humans and domesticated animals (Naughton et al., 1995, 1996a, 2000; Havelaar et al., 2001; Islam et al., 2000). Defined fimbriae- (SEF14, SEF17, SEF21, pef and lpf) and/or flagella-deleted mutants of $S$. Enteritidis and their wild-type parent strains were tested in this infection model.

\section{METHODS}

Animal studies. Male specific-pathogen-free (SPF) Hooded-Lister rats (Rowett strain), bred in the small animal unit of the Rowett Research Institute, were used. Immediately after weaning (19 days), the rats were housed individually in grid-floor caging within a facility separate from other animals and given free access to high-quality semisynthetic diet (100 g lactalbumin protein $\mathrm{kg}^{-1}$ diet; Grant et al., 2000) and water. This was done to reduce environmental exposure to exogenous bacteria and prevent cross-contamination. The levels of bacteria resident in the small intestine of rats managed in this manner were generally significantly lower than those for standard SPF rats (Grant, 1996). When the rats had reached approximately $85 \mathrm{~g}$ (around 30 days old), their food intake was gradually reduced over a 3-4 day period to $7 \mathrm{~g} \mathrm{day}^{-1}$ per rat, given as two feeds over the day. This was the mean daily free intake for rats of the same age after oral infection with $S$. Enteritidis and around $70 \%$ of the free intake of this diet by noninfected animals. Rats were then transferred from the main animal unit to a Class II facility where they were housed singly in metabolism cages (Techniplast) within a flexi-film isolator (Moredun Animal Health). The rats were weighed daily.

Prior to inoculation, food was removed overnight. Rats (five per treatment) were then given $1 \mathrm{ml}$ (approx. $10^{8}$ c.f.u.) of the appropriate $S$. Enteritidis wild-type or deletion-mutant strain or $1 \mathrm{ml}$ culture medium by gavage. Rats were then returned to their cages. One or $3 \mathrm{~h}$ later, groups of five rats were killed by halothane (Rhodia Organique Fine) overdose and exsanguination. The abdomen was opened and tissues were removed aseptically and processed. The remaining rats were fed lactalbumin-based diet $\left(7 \mathrm{~g} \mathrm{day}^{-1}\right.$ per rat) and were killed by halothane overdose and exsanguination at 24 or $72 \mathrm{~h}$ post-infection (p.i.).

The stomach and the small intestine were flushed with PBS $(\mathrm{pH} 7 \cdot 2)$ to remove contents and non-adherent bacteria. Twenty $\mathrm{cm}$ of jejunum $(5-25 \mathrm{~cm}$ from the pylorus) and $20 \mathrm{~cm}$ of ileum $(5-25 \mathrm{~cm}$ from the ileo-caecal junction) were removed. These and the stomach tissue, caecum plus contents, colon plus contents, mesenteric lymph node and representative proportions of the liver and spleen were processed for viable counts. The remaining small intestine (about $40 \mathrm{~cm}$ ), liver and spleen was frozen in liquid nitrogen, weighed, freeze-dried and reweighed.

The Rowett Research Institute is licensed under the UK Animals (Scientific Procedures) Act 1986. The ethical review committee and the animal welfare unit of the institute and the appropriate governmental inspectorate monitor and review all animal studies. The management and experimental procedures undertaken were approved by the ethical committee and done in strict accordance with the requirements of the Act by staff licensed to carry out such procedures.

Culture of bacteria. S. Enteritidis strains LA5 and S1400/94 were originally isolated from poultry infections and have been characterized previously (Allen-Vercoe et al., 1999; Allen-Vercoe \& Woodward, 1999; Walker et al., 1999; Cooper et al., 1990). The isogenic mutant strains used (Table 1) were constructed by insertional mutagenesis and have been characterized previously (Allen-Vercoe \& Woodward, 1999). Stocks, maintained on Dorset egg slopes at $4{ }^{\circ} \mathrm{C}$, were subcultured on to nutrient agar plates and grown at $37^{\circ} \mathrm{C}$ overnight. Five to ten colonies from the plate were inoculated into $10 \mathrm{ml}$ Luria-Bertani broth and incubated with agitation at $37^{\circ} \mathrm{C}$ overnight to give approximately $10^{8}$ c.f.u. $\mathrm{ml}^{-1}$.

Tissue samples were weighed and then homogenized in $10 \mathrm{ml}$ maximum recovery diluent (MRD; Fisher Scientific) using a Janke-Kunkel Ultra-Turrax T25 tissue homogenizer at 20000 r.p.m. for 30 s. Up to six sequential dilutions $(1: 10, \mathrm{v} / \mathrm{v})$ of the primary homogenate were made

\section{Table 1. Genotypes of $S$. Enteritidis mutant strains}

Genotype of wild-type strains: SEF14+, SEF17+, SEF21+ (S. Enteritidis fimbriae 14, 17, $21 \mathrm{kDa}$ ), $\mathrm{PEF}+$ (plasmid-encoded fimbriae), LPF+ (long polar fimbriae), FLA+ (flagellate). EAV9 and EAV10 are flagelladeleted mutants (fla-) respectively derived from S1400/94 and LA5. EAV26 is a multiple fimbriae-deleted mutant (fim-) of S1400/94. EAV37 is a combined fim - and fla - mutant of S1400/94. Abbreviations: MSHA, mannose-sensitive agglutination; amp, ampicillin; cam, chloramphenicol; kan, kanamycin; tet, tetracycline; trim, trimethoprim; zeo, zeocin.

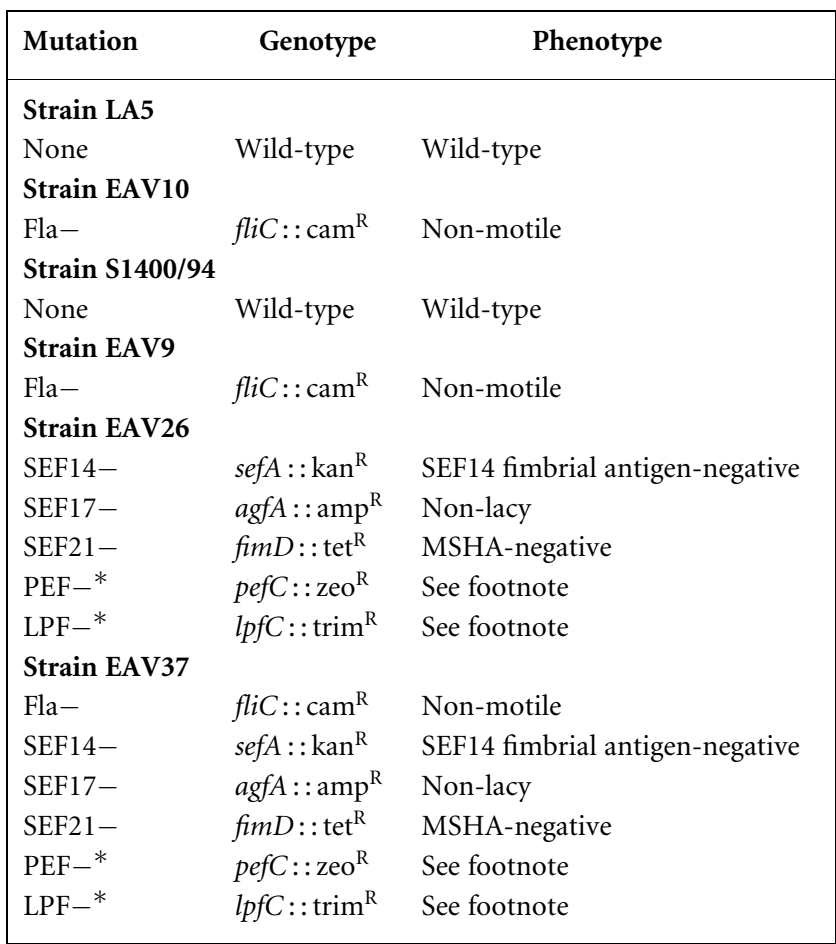

* Genotypic evidence only of insertional inactivation of pef and lpf genes (Allen-Vercoe \& Woodward, 1999). 
in MRD. Samples of each dilution were plated onto the surface of welldried XLD agar (Fisher Scientific) plates and incubated overnight at $37^{\circ} \mathrm{C}$. Viable counts were estimated by the method of Miles \& Misra (1938) or by a spread plate method (Collins et al., 1989).

Determination of myeloperoxidase (MPO) activity. Freeze-dried intestine samples were homogenized $(1: 20, \mathrm{w} / \mathrm{v})$ in ice-cold $0.5 \mathrm{M}$ potassium phosphate $(\mathrm{pH} 6 \cdot 0)$ containing hexadecyltrimethylammonium bromide (HETAB, $5 \mathrm{~g} \mathrm{l}^{-1}$ ) and EDTA $\left(3.72 \mathrm{~g} \mathrm{l}^{-1}\right.$ ) (Stein et al., 1998; Faro et al., 2000). They were left on ice for $60 \mathrm{~min}$ and then centrifuged $\left(3000 \mathrm{~g}, 30 \mathrm{~min}, 4{ }^{\circ} \mathrm{C}\right)$. MPO activity in the extracts was determined by monitoring $\mathrm{H}_{2} \mathrm{O}_{2}$-dependent oxidation of $3,3^{\prime}, 5,5^{\prime}$ tetramethylbenzidine (TMB; Dynex Technologies) in $50 \mathrm{mM}$ potassium phosphate buffer (pH 6.0) (Zimmerman \& Granger, 1990). $A_{450}$ was measured after termination of the reaction with $0 \cdot 18 \mathrm{M} \mathrm{H}_{2} \mathrm{SO}_{4}$. Human MPO (Calbiochem) was used as a standard and values were expressed as MPO $(\mu \mathrm{g})$ equivalents.

Determination of elastase content. Freeze-dried faeces were extracted $(1: 10, \mathrm{w} / \mathrm{v})$ in ice-cold $0.5 \mathrm{M}$ potassium phosphate $(\mathrm{pH} 6 \cdot 0)$ containing HETAB, EDTA and $\mathrm{NaN}_{3}\left(1 \mathrm{~g} \mathrm{l}^{-1}\right)$, left on ice for $30 \mathrm{~min}$ and then centrifuged $\left(3000 \mathrm{~g}, 30 \mathrm{~min}, 4{ }^{\circ} \mathrm{C}\right)$. Sample extract or leukocyte-elastase (Sigma-Aldrich) was serially diluted in $0 \cdot 2 \mathrm{M}$ Tris/ $\mathrm{HCl}(\mathrm{pH} 8.0)$ containing $1 \mathrm{M} \mathrm{NaCl}$ and leupeptin $\left(1 \mathrm{mg} \mathrm{l}^{-1}\right)$ on a microtitre plate. Substrate ( $N$-succinyl-Ala-Ala-Val $p$-nitroanilide, $0 \cdot 2 \mathrm{~g} \mathrm{l}^{-1}$; Sigma-Aldrich) was added and the $A_{405}$ was monitored immediately and at intervals up to $4 \mathrm{~h}$ during incubation at $37^{\circ} \mathrm{C}$ (Zimmerman \& Granger, 1990). Values were expressed as leukocyteelastase $(\mu \mathrm{g})$ equivalents. Faecal trypsin was assayed as a marker of pancreas enzyme output using $N$ - $\alpha$-benzoyl-DL-arginine $p$-nitroanilide (BAPNA) as substrate and bovine trypsin as standard (Grant et al., 2000).

Monitoring of acid tolerance. A $100 \mu \mathrm{l}$ aliquot of an overnight culture of $S$. Enteritidis (fim $+/$ fla + , fim $-/$ fla,+ fim $+/$ fla - or fim $-/$ fla - ) was inoculated into $5 \mathrm{ml}$ Luria-Bertani broth and incubated with agitation at $37^{\circ} \mathrm{C}$ until an $\mathrm{OD}_{600}$ of $0 \cdot 2$ was attained. Luria-Bertani broth $\mathrm{pH} 7.0$ or acidified to $\mathrm{pH} 3.0$ by addition of $\mathrm{HCl}$ was then inoculated with $100 \mu \mathrm{l}$ of this exponential-phase culture and incubated with agitation at $37^{\circ} \mathrm{C}$ for up to $24 \mathrm{~h}$. Growth was measured by recording $\mathrm{OD}_{600}$.

Statistical analysis. Data were assessed by one-way analysis of variance in combination with the Tukey multiple comparison test using the INSTAT statistical package (GraphPad Software Inc.).

\section{RESULTS}

\section{Colonization and invasion in vivo}

S. Enteritidis strain LA5 spread rapidly throughout the whole gastrointestinal tract (Table 2). Furthermore, significant numbers were detectable in the mesenteric lymph nodes from $1 \mathrm{~h}$ through to $24 \mathrm{~h}$ p.i. Despite this, no salmonella were found in the spleen until $24 \mathrm{~h}$, at which time up to 160 c.f.u. per spleen could be detected. The numbers in the liver were low ( $\leqslant 300$ c.f.u. per tissue) at $3 \mathrm{~h}$ but increased significantly by $24 \mathrm{~h}$ (1000-4000 c.f.u. per tissue). S. Enteritidis strain S1400 also colonized the gut and systemic tissues (Table 3). Its distribution throughout the body at $24 \mathrm{~h}$ p.i. was broadly similar to that found for LA5, although the levels in the spleen were considerably higher (160-2500 c.f.u. per tissue) than for LA5. After $72 \mathrm{~h}$, the numbers of S1400 in the jejunum were slightly lowered (Table 3 ). However, this reduction was not evident in other regions of the gut or in the systemic tissues.

EAV10 and EAV9, the flagella-deleted (fim $+/$ fla - ) mutants, also colonized the gut and systemic tissues (Tables 2 and 3 ). However, their ability to reach or survive in the liver and spleen appeared to be impaired in the short-term. Thus, at $24 \mathrm{~h}$, EAV9 was found in the liver (50-500 c.f.u.) and spleen (5-160 c.f.u.) in much smaller numbers than its parent strain, S1400 (160-4000 c.f.u. per liver; 160-2500 c.f.u. per spleen). However, by $72 \mathrm{~h}$, the levels of EAV9 (15004000 c.f.u. per liver; $1000-2500$ c.f.u. per spleen) had increased and were comparable to those for S1400 (12005000 c.f.u. per liver; $1000-10000$ c.f.u. per spleen). The numbers of EAV10 in the liver (80-500 c.f.u.) at $24 \mathrm{~h}$ were also smaller than for its parent strain, LA5 (1000-4000 c.f.u.

\section{Table 2. Detection of Salmonella cells after oral dosage with strain LA5 or its aflagellate mutant, EAV10}

Values are $\log _{10}$ c.f.u. $\mathrm{g}^{-1}$. Rats $(n=5)$ were dosed orally with $10^{8}$ c.f.u. of the strain shown. Values in a row with distinct superscripts differ significantly $(P \leqslant 0 \cdot 05)$. MLN, Mesenteric lymph nodes; NS, not sampled. The limit of detection is 1.0 for liver and spleen. For comparison purposes, zero values (no colonies detected) are given as the limit of detection.

\begin{tabular}{|c|c|c|c|c|c|c|}
\hline \multirow[t]{2}{*}{ Tissue } & \multicolumn{2}{|c|}{$1 \mathrm{~h}$} & \multicolumn{2}{|c|}{$3 \mathrm{~h}$} & \multicolumn{2}{|c|}{$24 \mathrm{~h}$} \\
\hline & LA5 & EAV10 & LA5 & EAV10 & LA5 & EAV10 \\
\hline Stomach & $5 \cdot 3 \pm 0 \cdot 8^{a b}$ & $4 \cdot 6 \pm 0 \cdot 8^{a}$ & $4 \cdot 5 \pm 0 \cdot 5^{a}$ & $3 \cdot 4 \pm 0 \cdot 6^{a}$ & $6 \cdot 4 \pm 1 \cdot 1^{b}$ & $4 \cdot 4 \pm 0 \cdot 8^{a}$ \\
\hline Jejunum & $4 \cdot 2 \pm 0 \cdot 7$ & $3 \cdot 6 \pm 0 \cdot 7$ & $3 \cdot 2 \pm 0 \cdot 7$ & $4 \cdot 1 \pm 1 \cdot 4$ & $4 \cdot 4 \pm 0 \cdot 7$ & $3 \cdot 2 \pm 0 \cdot 9$ \\
\hline Ileum & $8 \cdot 1 \pm 0 \cdot 6^{a}$ & $7 \cdot 9 \pm 0 \cdot 6^{a}$ & $6 \cdot 2 \pm 0 \cdot 6^{b}$ & $6 \cdot 6 \pm 0 \cdot 8^{b}$ & $6 \cdot 2 \pm 0 \cdot 6^{b}$ & $6 \cdot 1 \pm 0 \cdot 5^{b}$ \\
\hline Caecum & NS & NS & $8 \cdot 3 \pm 0 \cdot 3$ & $8 \cdot 5 \pm 0 \cdot 2$ & $7 \cdot 4 \pm 0 \cdot 5$ & $7 \cdot 9 \pm 0 \cdot 8$ \\
\hline Colon & NS & NS & $7 \cdot 5 \pm 1 \cdot 1$ & $7 \cdot 3 \pm 0 \cdot 7$ & $7 \cdot 5 \pm 0.9$ & $7 \cdot 4 \pm 0 \cdot 5$ \\
\hline MLN & $4 \cdot 4 \pm 1 \cdot 6$ & $3 \cdot 5 \pm 0 \cdot 8$ & $5 \cdot 1 \pm 1 \cdot 1$ & $4 \cdot 3 \pm 0 \cdot 4$ & $5 \cdot 0 \pm 0 \cdot 3$ & $4 \cdot 9 \pm 1 \cdot 0$ \\
\hline Liver & NS & NS & $1 \cdot 3 \pm 0 \cdot 6^{a}$ & $1 \cdot 4 \pm 0 \cdot 3^{a}$ & $2 \cdot 7 \pm 0 \cdot 3^{b}$ & $1 \cdot 7 \pm 0 \cdot 4^{a}$ \\
\hline Spleen & NS & NS & $1 \cdot 0 \pm 0 \cdot 0^{a}$ & $1 \cdot 0 \pm 0 \cdot 0^{a}$ & $1 \cdot 9 \pm 0 \cdot 9^{b}$ & $2 \cdot 3 \pm 0 \cdot 4^{b}$ \\
\hline
\end{tabular}


Table 3. Detection of Salmonella cells after oral dosage with strain S1400 and its mutants

Tissues were sampled 24 or $72 \mathrm{~h}$ after oral dosage as shown. See legend to Table 2 for further details. Strain EAV26 is unable to express SEF14, SEF17, SEF21, pef and lpf.

\begin{tabular}{|lllll|}
\hline Tissue & $\begin{array}{c}\text { S1400 } \\
(\mathbf{f i m}+/ \mathbf{f l a}+)\end{array}$ & $\begin{array}{c}\text { EAV9 } \\
(\mathbf{f i m}+/ \mathbf{f l a}-)\end{array}$ & $\begin{array}{c}\text { EAV26 } \\
(\mathbf{f i m}-/ \mathbf{f l a}+)\end{array}$ & $\begin{array}{c}\text { EAV37 } \\
(\mathbf{f i m}-/ \text { fla- }\end{array}$ \\
\hline 24 h p.i. & & & & \\
Stomach & $4 \cdot 1 \pm 0 \cdot 6^{a}$ & $3 \cdot 9 \pm 0 \cdot 7^{a}$ & $4 \cdot 1 \pm 0 \cdot 7^{a}$ & $2 \cdot 9 \pm 0 \cdot 2^{b}$ \\
Jejunum & $5 \cdot 4 \pm 0 \cdot 8^{a}$ & $4 \cdot 0 \pm 1 \cdot 1^{a b}$ & $4 \cdot 9 \pm 1^{a}$ & $2 \cdot 9 \pm 0 \cdot 5^{b}$ \\
Ileum & $6 \cdot 2 \pm 0 \cdot 3$ & $5 \cdot 7 \pm 0 \cdot 5$ & $6 \cdot 3 \pm 0 \cdot 3$ & $5 \cdot 7 \pm 0 \cdot 5$ \\
Caecum & $6 \cdot 8 \pm 1 \cdot 0^{a}$ & $8 \cdot 8 \pm 0 \cdot 6^{b}$ & $7 \cdot 8 \pm 0 \cdot 5^{a b}$ & $6 \cdot 6 \pm 0 \cdot 4^{a}$ \\
Colon & $6 \cdot 3 \pm 0 \cdot 5^{a}$ & $8 \cdot 0 \pm 0 \cdot 6^{b}$ & $7 \cdot 7 \pm 0 \cdot 8^{b}$ & $6 \cdot 2 \pm 0 \cdot 4^{a}$ \\
MLN & $5 \cdot 3 \pm 0 \cdot 7$ & $4 \cdot 6 \pm 0 \cdot 3$ & $5 \cdot 5 \pm 0 \cdot 5$ & $4 \cdot 3 \pm 0 \cdot 6$ \\
Liver & $2 \cdot 3 \pm 0 \cdot 7^{a}$ & $1 \cdot 0 \pm 0 \cdot 1^{b}$ & $2 \cdot 8 \pm 0 \cdot 8^{a}$ & $1 \cdot 0 \pm 0 \cdot 3^{b}$ \\
Spleen & $3 \cdot 4 \pm 0 \cdot 6^{a}$ & $2 \cdot 1 \pm 0 \cdot 7^{b}$ & $3 \cdot 2 \pm 0 \cdot 5^{a}$ & $2 \cdot 3 \pm 0 \cdot 3^{b}$ \\
72 h p.i. & & & & \\
Stomach & $5 \cdot 2 \pm 0 \cdot 6^{a}$ & $3 \cdot 8 \pm 0 \cdot 6^{b}$ & $4 \cdot 7 \pm 0 \cdot 2^{a}$ & $3 \cdot 6 \pm 0 \cdot 7^{b}$ \\
Jejunum & $3 \cdot 4 \pm 0 \cdot 2^{a}$ & $2 \cdot 3 \pm 0 \cdot 5^{b}$ & $3 \cdot 5 \pm 0 \cdot 4^{a}$ & $2 \cdot 1 \pm 0 \cdot 1^{b}$ \\
Ileum & $5 \cdot 7 \pm 0 \cdot 5$ & $5 \cdot 4 \pm 0 \cdot 3$ & $5 \cdot 6 \pm 0 \cdot 3$ & $5 \cdot 8 \pm 0 \cdot 2$ \\
Caecum & $5 \cdot 8 \pm 1 \cdot 8$ & $6 \cdot 0 \pm 0 \cdot 5$ & $5 \cdot 2 \pm 0 \cdot 8$ & $5 \cdot 2 \pm 0 \cdot 8$ \\
Colon & $5 \cdot 8 \pm 0 \cdot 2$ & $5 \cdot 8 \pm 0 \cdot 6$ & $5 \cdot 2 \pm 1 \cdot 0$ & $6 \cdot 1 \pm 0 \cdot 6$ \\
MLN & $5 \cdot 3 \pm 0 \cdot 7$ & $5 \cdot 4 \pm 0 \cdot 2$ & $5 \cdot 3 \pm 0 \cdot 1$ & $5 \cdot 3 \pm 0 \cdot 2$ \\
Liver & $2 \cdot 8 \pm 0 \cdot 3$ & $2 \cdot 8 \pm 0 \cdot 2$ & $2 \cdot 7 \pm 0 \cdot 2$ & $2 \cdot 4 \pm 0 \cdot 3$ \\
Spleen & $4 \cdot 1 \pm 0 \cdot 5$ & $3 \cdot 8 \pm 0 \cdot 2$ & $3 \cdot 7 \pm 0 \cdot 2$ & $3 \cdot 6 \pm 0 \cdot 2$ \\
\hline
\end{tabular}

Table 4. Small intestine tissue composition and faecal excretion by rats infected with strain $\mathrm{S} 1400$ and its mutants

See legend to Table 2 for further details.

\begin{tabular}{|c|c|c|c|c|c|}
\hline Measure & Control & $\begin{array}{c}\mathrm{S} 1400 \\
(\text { fim }+/ \text { fla }+)\end{array}$ & $\begin{array}{c}\text { EAV9 } \\
(\text { fim }+/ \text { fla }-)\end{array}$ & $\begin{array}{c}\text { EAV26 } \\
(\text { fim-/fla }+)\end{array}$ & $\begin{array}{c}\text { EAV37 } \\
(\text { fim-/fla-) }\end{array}$ \\
\hline \multicolumn{6}{|l|}{ Small intestine (24 h) } \\
\hline Water (mg) & $2289 \pm 155$ & $2292 \pm 120$ & $2224 \pm 81$ & $2504 \pm 210$ & $2239 \pm 190$ \\
\hline MPO $(\mu \mathrm{g})$ & $27 \cdot 7 \pm 6 \cdot 6$ & $36 \cdot 8 \pm 7 \cdot 4$ & $27 \cdot 1 \pm 7 \cdot 5$ & $35 \cdot 3 \pm 3 \cdot 6$ & $25 \cdot 1 \pm 8 \cdot 0$ \\
\hline Water (mg) & $2331 \pm 160^{a}$ & $2981 \pm 325^{b}$ & $2575 \pm 292^{a b}$ & $3130 \pm 324^{b}$ & $2725 \pm 250^{a b}$ \\
\hline $\mathrm{MPO}(\mu \mathrm{g})$ & $27 \cdot 7 \pm 6 \cdot 6^{a}$ & $65 \cdot 2 \pm 9 \cdot 0^{b}$ & $47 \cdot 8 \pm 10 \cdot 9^{a b}$ & $60 \cdot 1 \pm 10 \cdot 2^{b}$ & $35 \cdot 7 \pm 8 \cdot 9^{a}$ \\
\hline \multicolumn{6}{|l|}{ Faeces $(24 \mathrm{~h})$} \\
\hline Salmonella $\left(\log _{10}\right.$ c.f.u. $\left.\mathrm{g}^{-1}\right)$ & 0 & $7 \cdot 1 \pm 1 \cdot 3$ & $7 \cdot 7 \pm 1 \cdot 1$ & $7 \cdot 2 \pm 0 \cdot 9$ & $7 \cdot 1 \pm 1 \cdot 4$ \\
\hline \multicolumn{6}{|l|}{ Faeces $(72 \mathrm{~h})$} \\
\hline
\end{tabular}

ND, Not determined; PMN, polymorphonuclear leukocyte.

per liver), but there appeared to be no differences between EAV10 (5-160 c.f.u.) and LA5 (up to 160 c.f.u.) in numbers present in the spleen (Table 2 ).

There was also a tendency for the flagella-deleted mutant strains to be present in the stomach and/or jejunum in smaller numbers than their parent strains (Tables 2 and 3). In particular, at $72 \mathrm{~h}$, the numbers of EAV9 (fim+/fla-) associated with both tissues were greatly reduced (Table 3 ). Nonetheless, the lack of functional flagella did not seem to 
affect the ability of the bacterium to colonize and persist in other regions of the gut or in the mesenteric lymph nodes (Tables 2 and 3 ).

Failure to express five fimbriae (SEF14, SEF17, SEF21, pef and lpf) did not seem to impair colonization or systemic spread by $S$. Enteritidis (Table 3). The levels of EAV26 (fim-/ fla+) found throughout the gut, in the mesenteric lymph nodes and in the liver and spleen were thus similar to those for its parent strain, S1400 (fim+/fla+). Furthermore, at $72 \mathrm{~h}$, the tissue distribution observed with the multiple fimbriaeand flagella-deleted mutant EAV37 (fim-/fla-) was close to that seen with EAV9 (fim+/fla-), the related strain in which flagella expression alone was disabled. There were, however, some differences between these mutant strains at $24 \mathrm{~h}$. The $\mathrm{fim}+/ \mathrm{fla}-$ strain was detected in slightly larger numbers than the fim-/fla- strain in the stomach and jejunum, but not in other regions of the gut or the systemic tissues.

Inability to express SEF14, SEF17, SEF21, pef and lpf and/or flagella did not affect faecal shedding of $S$. Enteritidis significantly (Table 4). Thus, rats infected with S1400 $(\mathrm{fim}+/ \mathrm{fla}+)$, EAV9 $(\mathrm{fim}+/ \mathrm{fla}-), \operatorname{EAV} 26(\mathrm{fim}-/ \mathrm{fla}+)$ or EAV37 (fim-/fla-) excreted similar numbers of salmonella in faeces. This was consistent with the finding that the deletion-mutant and wild-type strains colonized and persisted equally well throughout the large intestine (Table 3 ).

\section{Intestinal and faecal markers}

Intestinal MPO levels were considerably elevated 3 days after infection of rats with $S$. Enteritidis S1400 $(\mathrm{fim}+/ \mathrm{fla}+)$ or EAV26 (fim-/flat) (Table 4). The changes induced by the flagella-deleted mutant EAV9 (fim $+/$ fla-) were much less marked, whilst EAV37 (fim-/fla-) caused only a limited increase in intestinal MPO. Intestinal tissue water content was also elevated as a result of infection with S1400 or EAV26 (Table 4). The changes were, however, slightly less pronounced after infection with EAV9 or EAV37. Furthermore, faecal elastase was greatly elevated following infection with S1400 but only slightly increased by EAV37.

\section{Acid tolerance in vitro}

Growth of $S$. Enteritidis S1400, EAV26, EAV9 and EAV37 in Luria-Bertani broth at $\mathrm{pH} 7 \cdot 0$ or $3 \cdot 0$ was monitored for up to $24 \mathrm{~h}$ (results not shown). The wild-type and mutant strains grew equally well at $\mathrm{pH} 7 \cdot 0$. Furthermore, there were no differences in their ability to tolerate acid conditions. All four strains remained viable for up to $4 \mathrm{~h}$ at $\mathrm{pH} 3.0$ but did not multiply. By $24 \mathrm{~h}$, the strains were no longer viable.

\section{DISCUSSION}

S. Enteritidis strains LA5 and S1400 colonized and invaded in a manner generally similar to that seen with other $S$. Enteritidis or $S$. Typhimurium strains (Naughton et al., 1995, 1996a, 2000; Havelaar et al., 2001; Islam et al., 2000). Thus, there was rapid distribution throughout the gastrointestinal tract, translocation to the mesenteric lymph nodes and spread to the liver and spleen of the rats. Significant numbers of viable salmonella were detected in the mesenteric lymph nodes even within $1 \mathrm{~h}$ of oral infection and in the liver and spleen by $24 \mathrm{~h}$. This systemic appearance of pathogen, particularly in liver and spleen, occurred much sooner than reported previously for conventional rats or mice (Islam et al., 2000; Baumler et al., 1996, 1997; Carter \& Collins, 1974; Garcia-Del Portillo et al., 1999). This may be linked to the rat strain used (Hooded-Lister), which has been kept as a closed colony for over 50 years, or perhaps to reduced levels of commensal bacteria in the small intestine (Grant, 1996). The commensal bacteria give a high degree of protection against infection (Ducluzeau, 1984) and invasion of salmonella occurs more rapidly in antibiotic-treated or ex-germ-free animals (Miller \& Bohnhoff, 1963; Que \& Hentges, 1985). A reduction in background flora, due to controlled management of the animals prior the start of the study, in combination with withdrawal of food overnight prior to dosing with the pathogen may have facilitated rapid and extensive attachment of the pathogen to the epithelium and promoted early translocation.

MPO levels in the rat small intestine were unchanged $24 \mathrm{~h}$ after infection with $S$. Enteritidis S1400 but were significantly elevated at $72 \mathrm{~h}$. Intestine tissue water content and faecal elastase was also increased at $72 \mathrm{~h}$. This suggests that active recruitment of neutrophils to the intestine (Darwin \& Miller, 1999; Stein et al., 1998; Faro et al., 2000; Zimmerman \& Granger, 1990; McCormick et al., 1995; Naughton et al., 1996a) may have occurred between 24 and $72 \mathrm{~h}$ p.i. These changes would be consistent with the infiltration of polymorphonuclear leukocytes and other inflammatory cells into gut tissue and the release of inflammatory cells into the lumen, previously observed in vivo (Naughton et al., 1995, 1996a, b).

Salmonella cells have to attach to or form a close association with the intestinal epithelium in order to establish and persist in the gut and subsequently invade the underlying tissues (Tsolis et al., 1999; Kingsley \& Baumler, 2000; Ohl \& Miller, 2001; Darwin \& Miller, 1999; Humphries et al., 2001). These initial interactions with gut cells were previously shown to be facilitated in vitro and in vivo by fimbrial adhesins expressed on the surface of the pathogen (Ohl \& Miller, 2001; Darwin \& Miller, 1999; Humphries et al., 2001; Baumler et al., 1997). Deletion of a particular fimbria or inhibition of its action can thus limit the ability of salmonella to colonize and invade in vitro and in vivo (Ohl \& Miller, 2001; Darwin \& Miller, 1999; Humphries et al., 2001; Baumler et al., 1997; Dibb-Fuller et al., 1999; Naughton et al., 2001).

In the present study, deletion of five fimbriae (SEF14, SEF17, SEF21, pef, lpf) did not, however, appear to disadvantage $S$. Enteritidis in vivo. The fim-/fla+ mutant (EAV26) was able to colonize the rat gut and invade to the systemic tissues as effectively as its fimbriate parent strain (S1400, fim+/fla+). This was consistent with earlier findings, that these strains bound equally well to rat and chick gut explants (AllenVercoe \& Woodward, 1999; Robertson et al., 2000) and 
caused similar levels of infection in 1-day-old chicks (AllenVercoe et al., 1999). The results suggest that, whilst SEF14, SEF17, SEF21, pef, lpf can have significant roles in the early stages of infection (Ohl \& Miller, 2001; Darwin \& Miller, 1999; Humphries et al., 2001; Baumler et al., 1996, 1997), their presence is not a prerequisite in all cases.

Salmonella cells can bind directly to exposed gut epithelial cells, including the $\mathrm{M}$ cells of the Peyer's patch regions, and this is likely to involve the fimbrial adhesins (Kingsley \& Baumler, 2000; Darwin \& Miller, 1999; Humphries et al., 2001). Alternatively, they may initially form a loose association with the mucus layer overlying the gut (Ensgraber et al., 1992; Worton et al., 1989) and subsequently move down close to the epithelial cells. The mucus layer in the rat ileum is deep, comprising around $30 \mu \mathrm{m}$ of firmly adherent mucus in close proximity to the villi and approximately $450 \mu \mathrm{m}$ of loosely adherent mucus (Atuma et al., 2001). Furthermore, a high proportion of $S$. Enteritidis cells in the ileum are found in this mucus layer (Robertson, 2000). The mucus is expected to act as a barrier against the pathogen. However, if the pathogen can penetrate deep into the mucus layer, it may also be protected from movement of lumenal digesta, peristalsis or exposure to secreted antimicrobial substances. Our results imply that $S$. Enteritidis may be able to interact with epithelial cells in the rat gut without the need for SEF14, SEF17, SEF21, pef or lpf to anchor them in place. The composition or distribution of the mucus layer in the mouse, the species most widely used to study the roles of fimbriae in infection, may differ significantly from that in the rat (Atuma et al., 2001; Rozee et al., 1982). Invasion by $S$. Enteritidis in rats appears to be primarily through enterocytes underlying the mucus layer (Robertson, 2000) whilst, in mice, the main route is via the $M$ cells of the Peyer's patch (Kingsley \& Baumler, 2000; Humphries et al., 2001). Fimbriae do have an involvement in salmonellosis in mice (Darwin \& Miller, 1999; Humphries et al., 2001; Baumler et al., 1996, 1997), but SEF14, SEF17, SEF21, pef and lpf do not appear to be prerequisites for infection of rats. This may be a result of differences between the species in the routes of pathogen uptake or the involvement of mucus in gut-pathogen interactions. Alternatively, since 12 putative fimbrial operons have been identified in $S$. Enteritidis (Townsend et al., 2001), it is possible that fimbriae other than SEF14, SEF17, SEF21, pef and lpf have roles in the interaction of salmonella with the rat gut.

Fimbriate/aflagellate $(\mathrm{fim}+/ \mathrm{fla}-)$ S. Enteritidis was detected in the stomach and proximal small intestine in significantly larger numbers than its fim-/fla- counterpart at $24 \mathrm{~h}$ p.i. The numbers declined thereafter and, by $72 \mathrm{~h}$, were comparable to those for the fim-/fla- strain. This might indicate that the fimbriae, although not prerequisites for infection in the rat, compensated transiently for loss of flagella and enabled the aflagellate strain to survive in the stomach and proximal intestine in the short-term.

Inability to express flagella modified the nature of the infection caused by $S$. Enteritidis in rats. In the initial $24 \mathrm{~h}$, aflagellate $(\mathrm{fim}+/ \mathrm{fla}-$ or fim-/fla-) mutants colonized the gastrointestinal tract and spread to the mesenteric lymph nodes as effectively as their flagellate $(\mathrm{fim}+/ \mathrm{fla}+$ or fim $-/$ $\mathrm{fla}+$ ) counterparts. However, after $72 \mathrm{~h}$, the numbers of the aflagellate strains detectable in the stomach and jejunum were greatly reduced. Inflammatory responses triggered in the small intestine by $S$. Enteritidis were less marked if the strains were aflagellate. Furthermore, aflagellate $(\mathrm{fim}+\mathrm{l}$ fla-or fim-/fla-) $S$. Enteritidis was not found in significant numbers in the liver or spleen at $24 \mathrm{~h}$. However, the levels increased thereafter and, by $72 \mathrm{~h}$, were as high as those for flagellate strains.

There appeared to be little difference in the ability of aflagellate $(\mathrm{fim}+/ \mathrm{fla}-$ or fim-/fla-) and flagellate $(\mathrm{fim}+/$ fla+ or fim-/fla+) $S$. Enteritidis strains to colonize the rat ileum in vivo. This was consistent with the findings of other studies in vivo (Ikeda et al., 2001; Schmitt et al., 2001). However, it contrasted with earlier results in vitro (AllenVercoe \& Woodward, 1999; Robertson et al., 2000), where the aflagellate strains were found to be less able to attach to rat ileum or chick gut explants (Allen-Vercoe \& Woodward, 1999; Robertson et al., 2000). The numbers of $S$. Enteritidis associating with the explants were, however, greatly influenced by the mucus layer (Robertson et al., 2000), which is particularly deep at the ileum (Atuma et al., 2001). On a gut explant, the mucus layer is static and of high viscosity. In contrast, due to movement along the gut facilitated by peristalsis and continuous renewal by mucins produced by goblet cells, it is relatively fluid/dynamic and of moderate viscosity in vivo (Forstner \& Forstner, 1994). The mucus layer on explants may therefore be impermeable to non-motile bacterial strains, whilst the more fluid/dynamic mucus layer in vivo remains accessible to both motile and non-motile strains. Histological studies did indeed indicate that similar numbers of aflagellate or flagellate $S$. Enteritidis cells were present within the mucus layer in vivo (Robertson, 2000). In this case, the results from the explant models clearly did not reflect the interactions in vivo. Nonetheless, the findings highlight the fact that relatively small changes in the characteristics of mucus may greatly affect the ability the salmonella to reach and interact with underlying epithelial cells. This is of particular relevance, since the composition and thickness of the mucus layer varies throughout the gastrointestinal tract and is significantly influenced by general health status (Atuma et al., 2001; Forstner \& Forstner, 1994).

In contrast to the situation in the ileum, aflagellate $(\mathrm{fim}+1$ fla- or fim-/fla-) $S$. Enteritidis strains were generally less able than flagellate (fim $+/$ fla + or fim $-/$ fla + ) strains to persist long-term in the stomach and proximal small intestine. Since the parent and mutant strains were equally susceptible to the action of strong acid in vitro, persistence in the stomach was unlikely to be due to differences in acid tolerance. Stomach contents are generally very acidic. However, the $\mathrm{pH}$ in the mucus layer immediately adjacent to the stomach epithelium is maintained close to neutral to protect the epithelial cells (Atuma et al., 2001; Edwards \& Puente, 1998). S. Enteritidis may survive in the stomach by moving into this neutralized 
microenvironment. Peristalsis and movement of digesta in the proximal small intestine is more extensive and rapid than in the distal regions (Weisbrodt, 1987). In addition, the mucus layer with which salmonella could associate is much thinner in the duodenum and jejunum than in other regions of the gut (Atuma et al., 2001). Lack of motility may limit the ability of aflagellate strains to reach and interact with the epithelium and persist in these harsh environments.

Aflagellate (fim+/fla - or fim-/fla-) S. Enteritidis mutants appeared to be less inflammatory for the gut than flagellate (fim $+/$ fla + or fim-/fla + ) wild-type strains. Recruitment of neutrophils into the gut is mediated by chemoattractant chemokines, such as IL-8 (Darwin \& Miller, 1999; McCormick et al., 1995; Gewirtz et al., 2001). Their release from epithelial cells is triggered by various pathogen factors ( $\mathrm{Ohl} \&$ Miller, 2001; Galan, 2001), but flagellin, the flagellar subunit protein FliC, is a particularly potent stimulus (Gewirtz et al., 2001; Eaves-Pyles et al., 2001). Flagella-deleted or FliCblocked mutants of $S$. Typhimurium thus have reduced effects on IL-8 secretion in vitro (Gewirtz et al., 2001) and are less deleterious to mice in vivo (Ikeda et al., 2001; Schmitt et al., 2001). Despite this, there appeared to be little difference in the abilities of aflagellate, FliC-blocked or flagellate strains to promote neutrophil recruitment and fluid secretion over $12-16 \mathrm{~h}$ in a ligated loop model in vivo (Ikeda et al., 2001; Schmitt et al., 2001). The results of the present study suggest that flagella-deleted mutants of $S$. Enteritidis were less able to trigger neutrophil recruitment to the gut in vivo than their flagellate counterparts. However, the differences were not apparent until 3 days p.i.

Aflagellate $(\mathrm{fim}+/ \mathrm{fla}-$ or fim-/fla-) and flagellate $(\mathrm{fim}+/$ fla + or fim-/fla+) $S$. Enteritidis strains seemed to be equally invasive in vivo, since they were able to breach the epithelial barrier and reach the mesenteric lymph nodes at the same time after infection and in very similar numbers. This contrasts with various findings in vitro, where aflagellate $S$. Enteritidis or $S$. Typhimurium strains were significantly less invasive to cells in culture (Dibb-Fuller et al., 1999; Schmitt et al., 2001).

Flagella-deleted mutants $(\mathrm{fim}+/ \mathrm{fla}-$ or $\mathrm{fim}-/ \mathrm{fla}-)$ of $S$. Enteritidis were detected in the liver and spleen in much smaller numbers than their flagellate (fim $+/$ fla + or fim-l $\mathrm{fla}+$ ) counterparts after $24 \mathrm{~h}$. There were, however, no differences in the numbers at $72 \mathrm{~h}$ p.i. The level of pathogen found in the liver and spleen depends on both the rate of transfer to the tissues from the mesenteric lymph nodes and the rates of clearance of pathogen from the liver and spleen. In a mouse model, spread of aflagellate $S$. Typhimurium to the spleen appeared to be slightly delayed (Schmitt et al., 2001). In addition, FliC-blocked S. Typhimurium strains appeared less able to persist or proliferate in the mouse spleen (Ikeda et al., 2001). In the present study, failure to proliferate in or rapid clearance from the liver and spleen could explain the smaller numbers of aflagellate $S$. Enteritidis found in these tissues at $24 \mathrm{~h}$. However, this appears unlikely, since the differences were transient. They may, therefore, have been due to delayed breakout from the mesenteric lymph nodes.

It is not clear why aflagellate $S$. Enteritidis would be less able to breach the mesenteric lymph node barrier. Aflagellate $(\mathrm{fim}+/ \mathrm{fla}-$ or fim $-/$ fla - ) and flagellate (fim $+/ \mathrm{fla}+$ or fim - / $\mathrm{fla}+)$ strains were found in the tissue in similar numbers at all time-points studied. However, flagellin triggers release of a range of chemokines and cytokines that modulate cellular metabolism and increase the permeability of the gut to bacteria (Gewirtz et al., 2001; Eaves-Pyles et al., 2001). These factors may also affect mesenteric lymph node function and facilitate breakout of salmonella. In the absence of flagellin, the barrier potential of the mesenteric lymph node may, at least in the short-term, be preserved, thereby limiting the spread of aflagellate pathogen to the liver and spleen.

Recent studies have shown that some systemic spread of salmonella can occur without drainage through the lymphatic system (Vazquez-Torres et al., 1999; Rescigno \& Borrow, 2001). Pathogen sampled subepithelially or even luminally by dendritic cells or CD18-expressing phagocytes can be transferred directly to the liver and spleen (Vazquez-Torres $e t$ al., 1999; Rescigno \& Borrow, 2001; Sierro et al., 2001). As with neutrophils (McCormick et al., 1995), recruitment of these phagocytes to the gut is likely to be mediated by chemoattractant chemokines (Rescigno \& Borrow, 2001; Sierro et al., 2001). Because of their inability to produce flagellin, aflagellate strains (fim $+/$ fla - or fim-/fla-) of salmonella may not trigger release of the appropriate chemoattractants to facilitate recruitment of dendritic cells or CD18-expressing phagocytes to the gut. This could limit the uptake of the aflagellate pathogen by this route.

\section{ACKNOWLEDGEMENTS}

The Scottish Executive Environment and Rural Affairs Department supported this work.

\section{REFERENCES}

Allen-Vercoe, E. \& Woodward, M. J. (1999). The role of flagella, but not fimbriae, in the adherence of Salmonella enterica serotype Enteritidis to chick gut explant. J Med Microbiol 48, 771-780.

Allen-Vercoe, E., Sayers, A. R. \& Woodward, M. J. (1999). Virulence of Salmonella enterica serotype Enteritidis aflagellate and afimbriate mutants in a day-old chick model. Epidemiol Infect 122, 395-402.

Atuma, C., Strugala, V., Allen, A. \& Holm, L. (2001). The adherent gastrointestinal mucus gel layer: thickness and physical state in vivo. Am J Physiol Gastrointest Liver Physiol 280, G922-G929.

Baumler, A. J., Tsolis, R. M. \& Heffron, F. (1996). The lpf fimbrial operon mediates adhesion of Salmonella typhimurium to murine Peyer's patches. Proc Natl Acad Sci U S A 93, 279-283.

Baumler, A. J., Tsolis, R. M. \& Heffron, F. (1997). Fimbrial adhesins of Salmonella typhimurium. Role in bacterial interactions with epithelial cells. Adv Exp Med Biol 412, 149-158.

Carter, P. B. \& Collins, F. M. (1974). The route of enteric infection in normal mice. J Exp Med 139, 1189-1203. 
Collins, C. H., Lyne, P. M. \& Grange, J. M. (1989). Microbiological Methods, 6th edn. Oxford: Butterworth-Heinemann.

Cooper, G. L., Nicholas, R. A., Cullen, G. A. \& Hormaeche, C. E. (1990). Vaccination of chickens with a Salmonella enteritidis aroA live oral Salmonella vaccine. Microb Pathog 9, 255-265.

Darwin, K. H. \& Miller, V. L. (1999). Molecular basis of the interaction of Salmonella with the intestinal mucosa. Clin Microbiol Rev 12, 405-428.

Dibb-Fuller, M. P., Allen-Vercoe, E., Thorns, C. J. \& Woodward, M. J. (1999). Fimbriae- and flagella-mediated association with and invasion of cultured epithelial cells by Salmonella enteritidis. Microbiology 145, $1023-1031$.

Ducluzeau, R. (1984). Microbial interactions in the digestive tract. In The Germ-free Animal in Biomedical Research, pp. 141-154. Edited by M. E. Coates \& B. E. Gustafsson. London: Laboratory Animals Ltd.

Eaves-Pyles, T., Murthy, K., Liaudet, L., Virag, L., Ross, G., Soriano, F. G., Szabo, C. \& Salzman, A. L. (2001). Flagellin, a novel mediator of Salmonella-induced epithelial activation and systemic inflammation: I $\mathrm{B} \alpha$ degradation, induction of nitric oxide synthase, induction of proinflammatory mediators, and cardiovascular dysfunction. J Immunol 166, 1248-1260.

Edwards, R. A. \& Puente, J. L. (1998). Fimbrial expression in enteric bacteria: a critical step in intestinal pathogenesis. Trends Microbiol 6, 282-287.

Ensgraber, M., Genitsariotis, R., Storkel, S. \& Loos, M. (1992). Purification and characterization of a Salmonella typhimurium agglutinin from gut mucus secretions. Microb Pathog 12, 255-266.

Faro, C. J., Reidelberger, R. D. \& Palmer, J. M. (2000). Suppression of food intake is linked to enteric inflammation in nematode-infected rats. Am J Physiol Regul Integr Comp Physiol 278, R118-R124.

Forstner, J. F. \& Forstner, G. G. (1994). Gastrointestinal mucus. In Physiology of the Gastrointestinal Tract, pp. 1255-1284. Edited by L. R. Johnson. New York: Raven Press.

Galan, J. E. (2001). Salmonella interactions with host cells: type III secretion at work. Annu Rev Cell Dev Biol 17, 53-86.

Garcia-Del Portillo, F., Pucciarelli, M. G. \& Casadesus, J. (1999). DNA adenine methylase mutants of Salmonella typhimurium show defects in protein secretion, cell invasion, and M cell cytotoxicity. Proc Natl Acad Sci U S A 96, 11578-11583.

Gewirtz, A. T., Simon, P. O., Jr, Schmitt, C. K., Taylor, L. J., Hagedorn, C. H., O'Brien, A. D., Neish, A. S. \& Madara, J. L. (2001). Salmonella typhimurium translocates flagellin across intestinal epithelia, inducing a proinflammatory response. J Clin Invest 107, 99-109.

Grant, G. (1996). Management of animal experiments. In Effects of Antinutrients on the Nutritional Value of Legume Diets, COST 98, pp. 44-51. Edited by S. Bardocz. Brussels: European Commission.

Grant, G., Alonso, R., Edwards, J. E. \& Murray, S. (2000). Dietary soya beans and kidney beans stimulate secretion of cholecystokinin and pancreatic digestive enzymes in 400-day-old Hooded-Lister rats but only soya beans induce growth of the pancreas. Pancreas 20, 305-312.

Havelaar, A. H., Garssen, J., Takumi, K., Koedam, M. A., Dufrenne, J. B., van Leusden, F. M., de La Fonteyne, L., Bousema, J. T. \& Vos, J. G. (2001). A rat model for dose-response relationships of Salmonella Enteritidis infection. J Appl Microbiol 91, 442-452.

Humphries, A. D., Townsend, S. M., Kingsley, R. A., Nicholson, T. L., Tsolis, R. M. \& Baumler, A. J. (2001). Role of fimbriae as antigens and intestinal colonization factors of Salmonella serovars. FEMS Microbiol Lett 201, 121-125.

Ikeda, J. S., Schmitt, C. K., Darnell, S. C. \& 8 other authors (2001). Flagellar phase variation of Salmonella enterica serovar Typhimurium contributes to virulence in the murine typhoid infection model but does not influence Salmonella-induced enteropathogenesis. Infect Immun 69, 3021-3030.
Islam, A. F., Moss, N. D., Dai, Y., Smith, M. S., Collins, A. M. \& Jackson, G. D. (2000). Lipopolysaccharide-induced biliary factors enhance invasion of Salmonella enteritidis in a rat model. Infect Immun 68, 1-5.

Kingsley, R. A. \& Baumler, A. J. (2000). Salmonella interactions with professional phagocytes. In Bacterial Invasion into Eukaryotic Cells, pp. 321-342. Edited by T. A. Oelschlaeger \& J. Hacker. New York: Kluwer Academic/Plenum.

McCormick, B. A., Miller, S. I., Carnes, D. \& Madara, J. L. (1995). Transepithelial signaling to neutrophils by salmonellae: a novel virulence mechanism for gastroenteritis. Infect Immun 63, 2302-2309.

Miles, A. A. \& Misra, S. S. (1938). The estimation of the bactericidal power of blood. J Hyg 38, 749.

Miller, C. P. \& Bohnhoff, M. (1963). Changes in the mouse's enteric microflora associated with enhanced susceptibility to Salmonella infection following streptomycin treatment. J Infect Dis 113, 59-66.

Naughton, P. J., Grant, G., Ewen, S. W. B., Spencer, R. J., Brown, D. S. Pusztai, A. \& Bardocz, S. (1995). Salmonella typhimurium and Salmonella enteritidis induce gut growth and increase the polyamine content of the rat small intestine in vivo. FEMS Immunol Med Microbiol 12, 251-258.

Naughton, P. J., Grant, G., Spencer, R. J., Bardocz, S. \& Pusztai, A. (1996a). A rat model of infection by Salmonella typhimurium or Salm. enteritidis. J Appl Bacteriol 81, 651-656.

Naughton, P. J., Clohessy, P. A., Grant, G., Pusztai, A. \& Golden, B. (1996b). Faecal calprotectin: non-invasive marker of gastrointestinal inflammation in Salmonella infected rats. Biochem Soc Trans 24, 308S.

Naughton, P. J., Grant, G., Bardocz, S. \& Pusztai, A. (2000). Modulation of Salmonella infection by the lectins of Canavalia ensiformis (Con A) and Galanthus nivalis (GNA) in a rat model in vivo. J Appl Microbiol 88, $720-727$.

Naughton, P. J., Grant, G., Bardocz, S., Allen-Vercoe, E., Woodward, M. J. \& Pusztai, A. (2001). Expression of type 1 fimbriae (SEF 21) of Salmonella enterica serotype enteritidis in the early colonisation of the rat intestine. J Med Microbiol 50, 191-197.

Ohl, M. E. \& Miller, S. I. (2001). Salmonella: a model for bacterial pathogenesis. Annu Rev Med 52, 259-274.

Que, J. U. \& Hentges, D. J. (1985). Effect of streptomycin administration on colonization resistance to Salmonella typhimurium in mice. Infect Immun 48, 169-174.

Rescigno, M. \& Borrow, P. (2001). The host-pathogen interaction: new themes from dendritic cell biology. Cell 106, 267-270.

Robertson, J. M. C. (2000). Roles of fimbriae and flagella during Salmonella enterica serovar Enteritidis infection in the rat. $\mathrm{PhD}$ thesis, University of Aberdeen, UK.

Robertson, J. M. C., Grant, G., Allen-Vercoe, E., Woodward, M. J., Pusztai, A. \& Flint, H. J. (2000). Adhesion of Salmonella enterica var Enteritidis strains lacking fimbriae and flagella to rat ileal explants cultured at the air interface or submerged in tissue culture medium. J Med Microbiol 49, 691-696.

Rozee, K. R., Cooper, D., Lam, K. \& Costerton, J. W. (1982). Microbial flora of the mouse ileum mucous layer and epithelial surface. Appl Environ Microbiol 43, 1451-1463.

Schmitt, C. K., Ikeda, J. S., Darnell, S. C., Watson, P. R., Bispham, J., Wallis, T. S., Weinstein, D. L., Metcalf, E. S. \& O'Brien, A. D. (2001). Absence of all components of the flagellar export and synthesis machinery differentially alters virulence of Salmonella enterica serovar Typhimurium in models of typhoid fever, survival in macrophages, tissue culture invasiveness, and calf enterocolitis. Infect Immun 69, $5619-5625$.

Sierro, F., Dubois, B., Coste, A., Kaiserlian, D., Kraehenbuhl, J. P. \& 
Sirard, J. C. (2001). Flagellin stimulation of intestinal epithelial cells triggers CCL20-mediated migration of dendritic cells. Proc Natl Acad Sci U S A 98, 13722-13727.

Stein, J., Ries, J. \& Barrett, K. E. (1998). Disruption of intestinal barrier function associated with experimental colitis: possible role of mast cells. Am J Physiol 274, G203-G209.

Townsend, S. M., Kramer, N. E., Edwards, R. \& 8 other authors (2001). Salmonella enterica serovar Typhi possesses a unique repertoire of fimbrial gene sequences. Infect Immun 69, 2894-2901.

Tsolis, R. M., Kingsley, R. A., Townsend, S. M., Ficht, T. A., Adams, L. G. \& Baumler, A. J. (1999). Of mice, calves, and men. Comparison of the mouse typhoid model with other Salmonella infections. Adv Exp Med Biol 473, 261-274.

Vazquez-Torres, A., Jones-Carson, J., Baumler, A. J. \& 7 other authors (1999). Extraintestinal dissemination of Salmonella by CD18-expressing phagocytes. Nature 401, 804-808.
Walker, S. L., Sojka, M., Dibb-Fuller, M. \& Woodward, M. J. (1999). Effect of $\mathrm{pH}$, temperature and surface contact on the elaboration of fimbriae and flagella by Salmonella serotype Enteritidis. J Med Microbiol 48, 253-261.

Weisbrodt, N. W. (1987). Motility of the small intestine. In Physiology of the Gastrointestinal Tract, pp. 631-663. Edited by L. R. Johnson, J. Christensen, M. J. Jackson, E. D. Jacobson \& J. H. Walsh. New York: Raven Press.

Worton, K. J., Candy, D. C., Wallis, T. S., Clarke, G. J., Osborne, M. P., Haddon, S. J. \& Stephen, J. (1989). Studies on early association of Salmonella typhimurium with intestinal mucosa in vivo and in vitro: relationship to virulence. J Med Microbiol 29, 283-294.

Zimmerman, B. J. \& Granger, D. N. (1990). Reperfusion-induced leukocyte infiltration: role of elastase. Am J Physiol 259, H390-H394. 